1 Title: Community assembly as a basis for tropical forest restoration in a 2 global change scenario

Running head: Community assembly as basis for restoration in a global change

6 Authors and adresses:

7 João Augusto Alves Meira-Neto ${ }^{1,2}$, Neil Damas de Oliveira-Júnior ${ }^{1,2}$, Nathália Silva ${ }^{1,2}$, Ary

8 Teixeira de Oliveira-Filho ${ }^{3}$, Marcelo Leandro Bueno ${ }^{1,2,4}$, Vanessa Pontara ${ }^{1,2,4}$, Markus 9 Gastauer ${ }^{1,2,5}$

${ }^{1}$ Universidade Federal de Viçosa, Laboratory of Ecology and Evolution of Plants - LEEP, Viçosa, Minas Gerais, Brazil, 36570-900.

2 Universidade Federal de Viçosa, Botany Graduate Program, Viçosa, Minas Gerais, Brazil, 36570-900.

${ }^{3}$ Universidade Federal de Minas Gerais, Botany Department of Universidade Federal de Minas Gerais, Belo Horizonte, Minas Gerais, Brazil, 31270-901.

${ }^{4}$ Laboratório de Evolução e Macroecologia, Universidade Estadual de Mato Grosso do Sul, BR 163, Mundo Novo, Mato Grosso do Sul, Brazil, 79980-000.

${ }^{5}$ Instituto Tecnológico Vale, Rua Boaventura da Silva, 955, Belém, Pará, Brazil, 66055-090.

*Corresponding author: João Augusto Alves Meira-Neto j.meira@ufv.br

Author contributions: JAAMN conceived, and designed the research; ATOF conceived the initial database; NDO, NS, MLB, ATOF, and VP built the database; JAAMN, and MG analyzed the data; MG contributed with statistical tools; JAAMN, NDO, NS, MLB, VL, and MG wrote, and edited the manuscript.

\begin{abstract}
Native tropical forests hold high levels of diversity, challenging forest restoration of large areas in a global change scenario. For a site-specific restoration is required the understanding of the main influences ruling the assemblages. We aimed to answer three questions. 1) how do environmental variables influence taxonomic, phylogenetic diversities, and the phylogenetic structure in the of Rio Doce Basin (TFRD)? 2) How do environmental variables, phylogenetic structure and the main types of seed dispersal relate to each other? 3) Which information of the TFRD assemblages can be used for ecological restoration and conservation? We used 78 sites with their checklists to calculate taxonomic, and phylogenetic diversities, phylogenetic structures, and dispersal proportions. Then, we related the diversities of the sites to their bioclimatic variables and built GLM models. Species richness was influenced negatively by water excess duration, by water deficit duration, and positively by maximum temperature, and temperature seasonality. Water regime drives diversity and phylogenetic community structure in the TFRD more than other variables. Annual precipitation and maximum temperature presented the clearer influences on diversity and phylogenetic structure. Zoochory was positively, and anemochory, autochory were negatively related to sesMPD. By choosing the lineages with high fitness for
\end{abstract}


44 each site, the functioning and the stability of ecosystems should increase. The addition of

45 species with anemochory and autochory increases functional and phylogenetic diversity in

46 areas with extreme water excess or water deficit, important in a global change scenario. A

47 high proportion of zoochory allows the communities to function conserving dispersers,

48 biodiversity, and services.

49

Keywords: Forest restoration, community assembly, phylogenetic diversity, dispersal types, 51 biodiversity conservation, global change.

\section{Implications for practice}

- The use of objective methods based on community assembly rules enhances the choice of species, and of phylogenetic lineages better fitted to the bioclimatic profiles of the areas to be restored, improving the functioning and stability of the restored forests.

- The water purification service should be improved through forest restoration as much as possible because ecosystem services and biodiversity conservation are cobenefits of restored forests.

- The inclusion of species with anemochory, and autochory in forest restoration practices should become usual, as they increase functional, and phylogenetic diversities, and as a consequence, the ecosystem stability.

- A large proportion of species with zoochory in restored forests co-benefits taxonomic diversity, phylogenetic diversity, and ecosystem stability. 


\section{Introduction}

Environmental degradation is one of the largest threats that are being looked at in the current global change scenario. Large-scale land degradation by agriculture, urbanization and mining are increasing in the tropics (Nazareno \& Vitule 2016; Nunes et al. 2019) and require forest restoration activities to reduce the loss of biodiversity and the loss of ecosystem services (Bustamante et al. 2019; Ellison et al. 2017; Filoso et al. 2017; Matos et al. 2020; Poorter et al. 2016). In the Brazilian Rio Doce Basin, the largest river basin $\left(86,715 \mathrm{~km}^{2}\right)$ fully inside the Atlantic Tropical Forest Domain, Brazil, a history of land degradation including a recent tailing dam collapse in 2015 (Edwards \& Laurance 2015; Meira et al. 2016; Meira-Neto \& Neri 2017), accumulated a vegetation deficit of 7,160 km2 to achieve compliance with actual environmental legislation (Pires et al. 2017). Native vegetation of the basin, mainly seasonal tropical forest, holds high levels of diversity (Neves et al. 2020), challenging the restoration of such large areas. Besides choosing the adequate site-specific restoration strategy (Brancalion et al. 2016; Holl \& Aide 2011), the selection of locally adapted species is necessary to restitute taxonomic, functional and phylogenetic diversities (Li et al. 2018; Temperton et al. 2005), safeguarding community stability and the performance of ecosystem services (Kang et al. 2018; Pillar et al. 2013), especially in global changing scenarios (Bakker \& Wilson 2004; Harris et al. 2006; Wolff et al. 2018). Thus, the understanding of the environmental influences ruling the vegetation assemblages is required to select locally adapted species for planting or seeding (Gastauer et al. 2018).

For deeper understanding of which factors are playing in the assemblage of those Tropical Forests of the Rio Doce Basin (TFRD), rules of community assembly can be assessed by means of tree species composition of forest remnants responding to environmental variables, influencing the taxonomic diversity as well as phylogenetic diversity and structure. This is because (Niño et al. 2014) ecological niches are major drivers of tropical communities largely determined by environmental variables that limit in different ways the species distributions (Götzenberger et al. 2012; Weiher et al. 2011; Weiher \& Keddy 1995).

Among the most usable niche determinants in vegetation are the bioclimatic variables (Fick \& Hijmans 2017a; Hijmans et al. 2005) which are capable of model spatial distributions of plant species for many different purposes (Austin 2007; Heringer et al. 2019; Phillips et al. 2006; Wüest et al. 2015) allowing predictions in plant communities based on niches (Carnaval \& Moritz 2008; Keddy 1992). Niche conservatism and niche convergence, as well as their effects on phylogenetic structures, are useful tools for empirical studies that evaluate environmental filtering and competition as causes of phylogenetic clustering and phylogenetic overdispersion, respectively (Boukili \& Chazdon 2017; Losos 2008; Swenson 2009; Wiens et al. 2010). As bioclimatic variables can filter in, and out lineages that have niches conserved or convergent, the phylogenetic structure may varies depending on the phylogenetic signal of selected traits (Blomberg et al. 2003; Lebrija-Trejos et al. 2010).

Besides ecological niches, the main dispersal types are also central in the community assembly since dispersal limitations can play an important rule for forests (Gilbert \& Lechowicz 2004; Hardy 2008; Hubbell 2001; Weber et al. 2014). Dispersal types are not only important as drivers of community assembly, but also can inform how these types are aligned with phylogenetic lineages and how these types are conserved or not in the phylogenetic lineages (i.e., phylogenetic signal) (Carrión et al. 2017; Chen et al. 2018).

Therefore, the knowledge about the community assembly of tropical forest communities with high biodiversity is essential for planning of restoration actions, 
113 increasing the stability and functioning of the restored and conserved ecosystems (Mori 114 2016; Oliver et al. 2015; Reich et al. 2012). Since phylogenetic ecology can shed light on the 115 understanding of rules of community assembly and ecological functioning of tropical forests 116 (González-Caro et al. 2014; Oliveira et al. 2014; Paine et al. 2012), we aimed to answer the 117 following questions. 1) How do bioclimatic variables influence taxonomic, and phylogenetic 118 diversities, and the phylogenetic structure in the tropical forests of a river basin (TFRD)? 2) 119 How do environmental variables, phylogenetic structure and the main types of seed 120 dispersal relate to each other in the TFRD assemblages? 3) What of the answers to the 121 previous questions can be used in the ecological restoration of TFRD, as well as in the conservation of biodiversity and ecosystem services?

\section{Material and Methods}

\section{Study sites/surveys}

This study was performed on Tropical Forests of the Rio Doce Basin (TFRD), located between latitudes $17^{\circ} 45^{\prime}$ and $21^{\circ} 15^{\prime} \mathrm{S}$ and longitudes $39^{\circ} 30^{\prime}$ and $43^{\circ} 45^{\prime} \mathrm{W}$, with more than $86.000 \mathrm{~km}^{2}$ occupying parts of Minas Gerais and Espírito Santo states in Brazil (Fig 1). The TFRD area may be influenced by different floras (i.e., Cerrado and Campos Rupestres) on western watersheds, and mountain tops, but Atlantic Tropical Forest flora defines the basin within the domain of Atlantic Forest. We analyzed woody species from subtypes of Atlantic Tropical Forests: seasonal tropical forest and tropical rainforest.

The seasonal tropical forest is defined by a seasonality characterized by a rainy season characteristic of tropical forests followed by a dry season during the winter. As a response to that seasonality, around $20-50 \%$ of the trees lose their leaves during the dry period (deciduous). The tropical rain forests are under tropical climate conditions with average temperature of $25^{\circ} \mathrm{C}$, and with a very well distributed precipitation along the year, characterized by tall evergreen trees (Oliveira-Filho \& Fontes 2000).

The TFRD limits are watersheds of Serra Negra, and Aimorés mountains northwards, the Espinhaço Range on west, the Brigadeiro, and the Caparaó Ranges on southeast, and the ocean in the east. The rainfall regime in the basin is generally divided into rainy season during the summer, and dry season during the winter. The Mean Annual Precipitation varies from 1200 to $1900 \mathrm{~mm}$. The soil of the TFRD are predominantly dystrophic Red-Yellow latosols, deep soils characterized by high aluminium contents, and dystrophic Red Cambisols, a type of shallower soils (Marangon et al. 2013; Nunes et al. 2000; Soil Department of Universidade Federal de Vicosa 2020).

The database has 78 locations of TFRD extracted from NeotropTree, with checklists of tree species (Oliveira-Filho 2014). The checklists are records of papers, monographs, dissertations and thesis as well herbaria records available in the Flora and Fungi Virtual Herbarium (2020). Because the high number of checklists for some sites, the data was compound into one checklist list. A total of 22007 trees of 1944 species within 100 families were analyzed for TFRD (Oliveira-Junior et al. 2020). 
We produced a phylogenetic tree with all woody angiosperms recorded in the basin using Phylomatic function in Phylocom 4.2 (Webb \& Donoghue 2005) and megatree R20160415.new (Gastauer \& Meira-Neto 2017) based on APG IV (The Angiosperm Phylogeny Group 2016). Ferns and gymnosperms were omitted because of their outcome on the phylogenetic metrics they are very distinct and old phylogenetic lineages.

We used the following metrics to explain phylogeny of TFRD in each community: (i) Faith's phylogenetic Index (PD) (Faith 1992) found by the sum of phylogenetic branches for all species ; (ii) Mean Pairwise Distance (MPD), the mean phylogenetic distance among species; (iii) Mean Nearest Taxon Distance (MNTD) (Webb 2000; Webb et al. 2002), the mean phylogenetic distance between the closest related species. Also, we calculated the standardized effect size (ses) of PD, MPD and MNTD to eliminate the richness effect based on a null model (Swenson 2014). Negative ses show phylogenetic clustering and positive ses show phylogenetic overdispersion.

We used evolutionary distinctiveness scores (ED) as species exclusivity (Isaac et al. 2007). If a species does not have close relatives in a community phylogeny, that species is considered unique and ED scores high (Edwards et al. 2017).

\section{Environmental variables}

For each localization of the surveys, we gathered elevation (United States Geological Survey 2019) and extracted the 14 bioclimatic variables from WorldClim: Annual Mean Temperature, Isothermality, Temperature Seasonality, Maximum Temperature of the Warmest Month, Minimum Temperature of Coldest Month, Mean Temperature of Wettest Quarter, Annual Precipitation, Precipitation of Wettest Month, Precipitation of Driest Month and Precipitation Seasonality (Fick \& Hijmans 2017b). Additionally, we used WaterExcDur, WaterExcSev, WaterDefDur and WaterDefSev from diagrams of Walter (Oliveira-Filho 2014; Walter 1986; Walter \& Lieth 1967) for modelling. All bioclimatic variables are derived from the monthly or daily temperature and rainfall values in order to produce ecologically important variables used for niche modelling with high consistency (García-Callejas \& Araújo 2016; Morales-Barbero \& Vega-Álvarez 2019). The applied bioclimatic variables signify annual means (Booth 2016; Kendal et al. 2018), seasonality (Hereford et al. 2017; Tonkin et al. 2017) and severe environmental factors (e.g., duration and severity of water excess and deficits) that influence species distribution and performance (e.g., Amissah et al., 2018).

\section{Phylogenetic signal of dispersal types}

Phylogenetic signal of dispersal types means the trend of species with zoochory, anemochory, and autochory to be more related than by chance or to be less related than by chance. If the signal shows the pool of species with a dispersal type more related between each other than null models, the phylogenetic signal is clustered and means that the dispersal type has been predominantly conserved within the phylogenetic lineages under niche conservatism. The opposite, when a signal shows the species less related than calculated by null models, the phylogenetic signal is overdispersed and means that the dispersal type is predominantly convergent (homoplasy). In order to test if dispersal types presented phylogenetic signal, the NRI among all species of the same dispersal type (DispersalNRI) was calculated. The same was calculated for NTI (DispersalNTI). This calculation was done reordering species labels 999 times through phylogeny. DispersalNRI values significantly greater than zero (more than $1.96 \mathrm{sd}$, and more than $-1.96 \mathrm{sd}$ ) indicate phylogenetic signal. Phylogenetic signal of dispersal type was considered significant when 
205

206

207

208

209

210

211

212

213

214

215

216

217

218

219

220

221

222

223

224

225

226

227

228

229

230

231

232

233

234

235

236

237

238

239

240

241

242

243

244

245

246

247

248

249

250 the observed MPD or MNTD occurred in the lowest 2.5\% of the null models (significance of 0.05) (Gastauer et al. 2017).

Modelling

To outline the environmental predictor variables that best describe species richness and phylogenetic structure of sampled tree communities, we build for each response variable a global general linearized model containing all 15 predictor variables.

We scaled the explaining variables. Then, we used the dredge function of the MuMIn package (Bartón 2018) to model-select all possible combinations of five or less uncorrelated predictive variables $(r<0.6$, https://github.com/rojaff/dredge $\mathrm{mc}$ ) that most parsimoniously explained our data. We considered models with five or less predictive variables to avoid overfitting. We used the Akaike Information Criterion (AIC) for selection of the best models (Symonds \& Moussalli 2011). All models with $\triangle$ AIC less than 2 were considered equally parsimonious. When more than one model was selected, we calculated model-averaged parameters and unconditioned standard errors weighted by the likelihood ratio using the 'model.avg' function of the MuMln package. The function performs significance tests for each predictor estimated in this average model. The resulting global models were confirmed by plotting residuals versus adjusted values as well as residuals versus predicts.

For modelling percentages of zoochorous, anemochorous and autochorous species within surveys, we build global models containing the same 15 environmental predictor variables plus species richness, ses.MPD, ses.MNTD and ses.PD. For model selection, we proceed as described above.

\section{Results}

Modelling species richness, only one global model containing five environmental variables was selected, with four significant trends (Table S1), indicating that richness is influenced negatively by water excess duration and by water deficit duration meanwhile is positively influenced by the Maximum temperature of the warmest month as well as is positively influenced by seasonal temperature (Figure 1).

For further response variables, more than one model was selected (Table S1). 14 models containing the all variables except Precipitation during Wet Period, and Minimum Temperature explain sesPD. However, only two trends were significant: annual precipitation reduces sesPD, and water excess duration increases sesPD (Table S2, Figure 2).

For ses.MPD, six models were selected containing 10 out of the 15 predictor variables (Tables S1, S2). In the averaged model, only two trends were significant: annual precipitation reduces and water excess duration increases sesMPD (Figure 2).

For ses.MNTD, the two significant trends were: increasing maximum temperature of the warmest month, and increasing isothermality increase sesMNTD (Table S2, Figure 2).

The percentage of zoochory species increases with increasing SesMPD, with water excess duration, with water deficit severity, and decreases with water excess severity (Figure 3).

The percentage of species with anemochory decreases with increasing sesMPD and increases with increasing water excess severity (Table S3, Figure 4).

The percentage of autochory increases as sesMPD decreases, as water deficit severity decreases, and is positively related to the water excess severity (Table S3, Figure 4). 
Anemochory, and autochory presented DispersalNRI clustered phylogenetically showing that these dispersal types are conserved within phylogenetic lineages throughout the phylogenetic tree (Table 1). Zoochory, and anemochory preented clustered DispersalNTI, showing that hese dispersal types are conserved within phylogenetic lineages towards the tips of the phylogenetic branches (Table 1).

\section{Discussion}

Water regime drives species richness and phylogenetic community structure in the TFRD more than other types of environmental variables. At least one among annual precipitation, water excess duration, water excess severity, and water deficit severity were significant in all averaged models, except for the model for sesMNTD. Species richness, sesPD, sesMPD and percentage of zoochory were affected by water excess duration. All dispersal types were explained partially by water excess severity. Temperature regime was the second mst important important regime. Maximum temperature of the warmest month and isothermality explained sesMNTD. Maximum temperature of the warmest month, and temperature seasonality explained partially species richness. Among the variables, water excess duration, annual precipitation, maximum temperature and isothermality influenced the phylogenetic diversity and phylogenetic structure. The effects of temperature on richness, and on sesMNTD suggest environmental filtering effects causing phylogenetic clustering driven by decreasing maximum temperature of the warmest month and decreasing isothermality (i.e., increasing temperature variation). Therefore, the lower temperature and the less temperature variation in different seasons, the more environmental filtering.

The percentage of species with zoochory, anemochory or autochory were related to phylogenetic structures (i.e., sesMPD) in different ways. Increasing zoochory increases phylogenetic distances between species (i.e., increasing sesMPD) meanwhile increasing anemochory, and autochory decrease phylogenetic distances between species (i.e., decreasing sesMPD). The opposite relation of zoochory with sesMPD was not because zoochory is convergent, but because the less zoochory, the more abiotic dispersion (i.e., anemochory + autochory) that is clustered for MPD (i.e., DispersalNRI more related than by chance), suggesting anemochory, and autochory as homologies in the TFRD metacommunity. Only zoochory decreased with increasing water excess severity, and appears to be the only dispersal type benefited with increasing water surplus. Water excess severity was positively related to anemochory, and autochory, and might be interpreted as stresses influencing positively these dispersal types. Water deficit severity influenced negatively autochory.

The answer of the first question shows how environmental variables influence taxonomic, and phylogenetic diversities as well as phylogenetic structure in the tropical forests of that large river basin (TFRD). Seven environmental variables were found to influence the taxonomic diversity, phylogenetic diversity and phylogenetic structure in averaged models: water excess duration, water excess severity, water deficit duration, water excess severity, maximum temperature, temperature seasonality, and isothermality. As water excesses and water deficits increase in number of days, the species richness decreases. As the maximum temperature and the temperature seasonality decrease, the species richness decrease. Thus, more days of water excesses or more days of water deficits in TFRD are associated with loss of species richness as well as lower maximum temperatures 
298 and lower temperature variation between seasons. Therefore, the found global model 299 shows that increasing the number of days with excess or deficit of water, decreasing 300 temperatures, and decreasing temperature variation, decrease species richness.

Still answering the first question, as annual precipitation decreases and there are more days of water excess, sesPD and sesMPD increase; as maximum temperature and isothermality increase, sesMNTD increases. Thus, the lower annual precipitation, the more water excess days, the higher temperature variation, and the higher maximum temperatures in TFRD, the greater the phylogenetic diversity and phylogenetic distances between species. However, as the more days with water excess (i.e., days with higher precipitation than evapotranspiration) cause higher SesPD and sesMPD, it is possibly because benefits the zoochory that is positively-related to mean phylogenetic distances (see zoochory discussion below). Therefore, higher precipitation promotes decreasing sesPDs and sesMPDs (i.e., phylogenetic clustering) in the TFRD similarly to effects of environmental filters found in tropical vegetation (Gastauer \& Meira-Neto 2013; Miazaki et al. 2015), but does not cause species richness loss. Phylogenetic effects in tropical vegetation that can be explained by plant-plant interactions, density-dependence effects (Cadotte \& Tucker 2017; Carrión et al. 2017; Kraft et al. 2015; Meira-Neto et al. 2018; Paine et al. 2012), and environmental filtering that has been reported as cause of phylogenetic effects in many different groups of species, especially plants. For instance, environmental filtering promotes phylogenetic effects in protists, in diatoms (Keck \& Kahlert 2019; Leibold et al. 2010; Singer et al. 2018), and likely causes phylogenetic clustering in plant communities of tropical forests when associated with species richness decreasing (Gastauer \& Meira-Neto 2013; Parmentier et al. 2014). Therefore, the increasing annual precipitation in the TFRD that shortens phylogenetic distances might be an environmental filter effect because of excessive water. High precipitation may cause temporarily flooding stresses (Bueno et al., 2014; Pontara et al., 2016), and, consequently, may filter out lineages without conserved traits of flooding tolerance, but species richness does not decreased with the increasing annual precipitation. Alternatively, increasing annual precipitation would promote competition, and/or density dependent effects. For instance, high precipitation might cause competition increasing, and higher density-dependent effects by increased water resources and increased plant growing (see Tilman 1988). However, the forests with largest trees in TFRD, which would indicate stronger competition, are in low altitude sites with lower precipitation (Camargos et al. 2008; Lopes et al. 2002; Souza et al. 2013, 2012). The only clear result is that as precipitation increases, PD, and MPD decrease as an effect of increasing percentages of species with abiotic dispersion (see dispersal discussion below). Therefore, environmental filtering, competition and density dependent effects do not explain the PD and the MPD variation in TFRD. On the other hand, temperature regime can explain environmental filtering because species richness and sesMNTD decrease as maximum temperature decreases, indicating that the lower the maximum temperature, the closer the relatives in the TFRD communities and the lower the species density. High and low temperatures have been reported as environmental filters in forests, but high temperatures are rather filters in tropical dry forests, and low temperatures are rather filters associated with high altitudes or latitudes in temperate forests (Qian 2018; Qian et al. 2014). Therefore, our results suggest that the seasonal TFRD are environmentally filtered by low temperatures that cause decreasing species richness, and decreasing phylogenetic distance between species of their communities by filtering in species with conserved traits within phylogenetic lineages. 
The second question was how the dispersal types relate with environmental variables and with phylogenetic structure in the TFRD assemblages. The percentage of species with zoochory, anemochory and autochory was significantly related to sesMPD and not to sesMNTD or SeSPD, which means that the main association of dispersal types with the communities' phylogenies is throughout the entire phylogenetic tree (i.e., sesMPD). As the DispersalNRI is clustered for abiotic dispersal types, the clustered sesMPD reinforce that anemochory and autochory are conserved in phylogenetic branches originated in old nodes congruently with the decreasing sesMPD as anemochory and autochory. As a consequence, the increasing proportion of zoochory is not caused by its preeminence as homoplasy in the TFRD metacommunity, but because abiotic dispersal decreases. Thus, increasing anemochory and autochory reduce the sesMPD distances between species congruently with their clustered DispersalNRI in the TFRD metacommunity.

Zoochory is phylogenetic clustered towards the tip of phylogenetic tree according to its DispersalMNTD. That means the species with zoochory are predominantly clustered in lineages with conserved zoochory diversified from recent nodes. Despite zoochory is clustered towards the tip of phylogenetic tree, zoochory is not clustered throughout the entire phylogenetic tree. Anemochory is also clustered clustered according to its DispersalMNTD. Autochory is not clustered towards the tip of phylogenetic tree in TFRD, suggesting lack of recent diversification of lineages with conserved autochory.

The dispersal types responded to water regime. The dominant dispersal type in TFRD is zoochory that varies from $50 \%$ up to more than $95 \%$ of the tree species in evergreen and seasonal Atlantic Tropical Forests (Tabarelli \& Peres 2002). In the TFRD, the minimum zoochory percentage found in a forest was $53 \%$ and the maximum was $81 \%$ (data not shown). As dominant dispersal type, zoochory responded positively to water excess duration, and water deficit severity meanwhile anemochory and autochory were not influenced by those explaining variables. However, zoochory responded in an opposite way from the two abiotic dispersal types to water excess severity. Zoochory also responded in an opposite way from autochory to water deficit severity. Thus, zoochory seems to be impaired meanwhile anemochory and autochory seem to be benefitted in sites with extreme severity of water excess or water deficit.

As anemochory and autochory are clustered in some phylogenetic branches in the TFRD metacommunity, the presence of these dispersal types in restored TFRD will allow those species to improve the functional and phylogenetic diversity of restored forests by representing entire phylogenetic branches, especially in those TFRD with extreme water regimes (i.e., high severity of water excess, and high severity of water deficit). Therefore, the relation between severity of water excess, and severity of water deficit with the two abiotic dispersal types deserves attention since extreme water regimes are increasing according to forecasted climate scenarios in the most of the Atlantic Forest distribution (IPCC 2013). As a consequence, the proportion of anemochory and autochory may increase in the TFRD during the next decades in a global change scenario.

Answering the question about what information from the TFRD community assembly can be used in ecological restoration, biodiversity conservation and conservation of ecosystem services, the results showed that the TFRD community assembly is central to large-scale forest restoration planned in the basin, including changing the effects of the Mariana disaster, a tailing dam that collapsed, and that compromised the service of the water purification in the basin. 1) The environmental filtering promoted by low temperatures (i.e., low maximum temperatures) drops the taxonomic diversity shortening 
392

393

394

395

396

397

398

399

400

401

402

403

404

405

406

407

408

409

410

411

412

413

414

415

416

417

418

419

420

421

422 the phylogenetic distance between species, predominantly filtering in species of some recently diversified lineages. Temperatures in TFRD are also related with altitude (data not shown). Thus, the use of some lineages better fitted for TFRD restoration in sites with low maximum temperatures (i.e., high altitudes inside the basin) should enhance the performance of restored forests. 2) Possibly the most affected ecosystem service by forests degradation, agriculture (Cabel et al. 1982), urbanization (Zhao et al. 2013), and environmental disasters (Lambertz \& Dergam 2015; Meira et al. 2016; Meira-Neto \& Neri 2017 ) is water purification that should be restored in all regions of the basin by means of forest restoration. We understand that tree species with good fitness to the bioclimatic profiles of restored sites will enhance the ecosystem service of water purification, especially in areas with low maximum temperature, and high annual precipitation, improving the functioning and the stability of restored forests (Cadotte et al. 2012, 2009; Isbell et al. 2015; Brancalion et al. 2016). 3) In a global change scenario that predicts increasing climate variance for TFRD (IPCC 2013), the inclusion of species with anemochory and autochory in restoration practices increases functional and phylogenetic diversity when associated with a large proportion of species with zoochory, especially in areas with extreme water excess or extreme water deficit. 4) A large proportion of species with zoochory in restored forests is mandatory because it assembles communities with high taxonomic, and phylogenetic diversity, conserving dispersal services (Jansen et al. 2014; Tabarelli \& Peres 2002), conserving dispersers, and conserving the threatened ecological interactions of tropical forests (Janzen 1986).

\section{Acknowledgements}

The authors thank the Botany Graduate Program (NS, VP) and the Ecology Graduate Program (MLB) for their support. The funding was provided by FAPEMIG (PPM-00584-16, APQ-01309-16), CAPES (PROAP fund and scholarships for NDO, VP, and MLB), and CNPq (NS scholarship, and 446698/2014-8). JAAMN holds a CNPq productivity fellowship (307591/2016-6). 


\section{Literature cited}

424

425

426

Amissah L et al. (2018) Rainfall seasonality and drought performance shape the distribution of tropical tree species in Ghana. Ecology and Evolution 8:8582-8597

Austin M (2007) Species distribution models and ecological theory: A critical assessment and some possible new approaches. Ecological Modelling 200:1-19

Bakker JD, Wilson SD (2004) Using ecological restoration to constrain biological invasion. Journal of Applied Ecology 41:1058-1064

Bartón K (2018) Package ‘MuMIn. 1.40.4.

Blomberg SP, Garland T, Ives AR (2003) Testing for Phylogenetic Signal in Comparative Data: Behavioral Traits Are More Labile. Evolution 57:717-745

Booth TH (2016) Estimating potential range and hence climatic adaptability in selected tree species. Forest Ecology and Management 366:175-183

Boukili VK, Chazdon RL (2017) Environmental filtering, local site factors and landscape context drive changes in functional trait composition during tropical forest succession. Perspectives in Plant Ecology, Evolution and Systematics 24:37-47

Brancalion PHS et al. (2016) Balancing economic costs and ecological outcomes of passive and active restoration in agricultural landscapes: the case of Brazil. Biotropica $48: 856-867$

Bueno ML et al. (2014) Structure of arboreal and herbaceous strata in a neotropical seasonally flooded monodominant savanna of Tabebuia aurea. Brazilian Journal of Biology 74:325-337 
445 Bustamante MMC et al. (2019) Ecological restoration as a strategy for mitigating and

446 adapting to climate change: lessons and challenges from Brazil. Mitigation and

$447 \quad$ Adaptation Strategies for Global Change 24:1249-1270

448 Cabel B et al. (1982) Pollution of drinking water with nitrate. Chemosphere 11:1147-1154

449 Cadotte MW et al. (2009) Using Phylogenetic, Functional and Trait Diversity to Understand

$450 \quad$ Patterns of Plant Community Productivity. PLOS ONE 4:e5695

451 Cadotte MW, Dinnage R, Tilman D (2012) Phylogenetic diversity promotes ecosystem

$452 \quad$ stability. Ecology 93:S223-S233

453 Cadotte MW, Tucker CM (2017) Should Environmental Filtering be Abandoned? Trends in

$454 \quad$ Ecology \& Evolution 32:429-437

455 Camargos VL de et al. (2008) Influência de fatores edáficos sobre variações florísticas na

456 Floresta Estacional Semidecídua no entorno da Lagoa Carioca, Parque Estadual do

457 Rio Doce, MG, Brasil. Acta Botanica Brasilica 22:75-84

458 Carnaval AC, Moritz C (2008) Historical climate modelling predicts patterns of current

459 biodiversity in the Brazilian Atlantic forest. Journal of Biogeography 35:1187-1201

460 Carrión JF et al. (2017) Facilitation as a driver of plant assemblages in Caatinga. Journal of $461 \quad$ Arid Environments

462 Chen K et al. (2018) Functional trade-offs and the phylogenetic dispersion of seed traits in a 463 biodiversity hotspot of the Mountains of Southwest China. Ecology and Evolution $464 \quad 8: 2218-2230$ 
465 Edwards DP, Laurance WF (2015) Preventing tropical mining disasters. Science 350:1482-

$466 \quad 1482$

467 Edwards DP et al. (2017) Tropical secondary forest regeneration conserves high levels of

468 avian phylogenetic diversity. Biological Conservation 209:432-439

469 Ellison D et al. (2017) Trees, forests and water: Cool insights for a hot world. Global

$470 \quad$ Environmental Change 43:51-61

471 Faith DP (1992) Conservation evaluation and phylogenetic diversity. Biological Conservation

$472 \quad 61: 1-10$

473 Fick SE, Hijmans RJ (2017a) WorldClim 2: new 1-km spatial resolution climate surfaces for

474 global land areas. International Journal of Climatology 37:4302-4315

475 Fick SE, Hijmans RJ (2017b) WorldClim 2: new 1-km spatial resolution climate surfaces for

476 global land areas. International Journal of Climatology 37:4302-4315

477 Filoso S et al. (2017) Impacts of forest restoration on water yield: A systematic review. PLOS

$478 \quad$ ONE 12:e0183210

479 García-Callejas D, Araújo MB (2016) The effects of model and data complexity on

480 predictions from species distributions models. Ecological Modelling 326:4-12

481 Gastauer M et al. (2018) Mine land rehabilitation: Modern ecological approaches for more

482 sustainable mining. Journal of Cleaner Production 172:1409-1422 
483 Gastauer M et al. (2017) Phylogenetic community structure reveals differences in plant

484 community assembly of an oligotrophic white-sand ecosystem from the Brazilian

$485 \quad$ Atlantic Forest. Acta Botanica Brasilica 0-0

486 Gastauer M, Meira-Neto JAA (2013) Interactions, Environmental Sorting and Chance:

487 Phylostructure of a Tropical Forest Assembly. Folia Geobotanica 49:443-459

488 Gastauer M, Meira-Neto JAA (2017) Updated angiosperm family tree for analyzing

489 phylogenetic diversity and community structure. Acta Botanica Brasilica 31:191-198

490 Gilbert B, Lechowicz MJ (2004) Neutrality, niches, and dispersal in a temperate forest

491 understory. Proceedings of the National Academy of Sciences of the United States of

$492 \quad$ America 101:7651-7656

493 González-Caro S et al. (2014) Phylogenetic alpha and beta diversity in tropical tree

494 assemblages along regional-scale environmental gradients in northwest South

$495 \quad$ America. Journal of Plant Ecology 7:145-153

496 Götzenberger L et al. (2012) Ecological assembly rules in plant communities-approaches,

497 patterns and prospects. Biological Reviews 87:111-127

498 Hardy OJ (2008) Testing the spatial phylogenetic structure of local communities: statistical

499 performances of different null models and test statistics on a locally neutral

$500 \quad$ community. Journal of Ecology 96:914-926

501 Harris JA et al. (2006) Ecological Restoration and Global Climate Change. Restoration

$502 \quad$ Ecology 14:170-176 
503 Hereford J, Schmitt J, Ackerly DD (2017) The seasonal climate niche predicts phenology and

504 distribution of an ephemeral annual plant, Mollugo verticillata. Journal of Ecology

$505 \quad 105: 1323-1334$

506 Heringer G et al. (2019) Can Acacia mangium and Acacia auriculiformis hinder restoration

507 efforts in the Brazilian Atlantic Forest under current and future climate conditions?

$508 \quad$ Biological Invasions

509 Hijmans RJ et al. (2005) Very high resolution interpolated climate surfaces for global land

$510 \quad$ areas. International Journal of Climatology 25:1965-1978

511 Holl KD, Aide TM (2011) When and where to actively restore ecosystems? Forest Ecology

$512 \quad$ and Management 261:1558-1563

513 Hubbell SP (2001) The Unified Neutral Theory of Biodiversity and Biogeography. Princeton

$514 \quad$ University Press, Princeton

515 IPCC (2013) Annex I: Atlas of Global and Regional Climate Projections. In: Climate Change

516 2013: The Physical Science Basis. contribution of Working Group I to the Fifth

517 Assessment Report on the Integovernmental Panel on Climate Change. van

518 Oldenborgh, G.J., M. Collins, J. Arblaster, J.H. Christensen, J. Marotzke, S.B. Power,

519 M. Rummukainen and T. Zhou (Eds). Cambridge University Press, Cambridge, United

$520 \quad$ Kingdom, and New York, NY, USA.

521 Isaac NJB et al. (2007) Mammals on the EDGE: Conservation Priorities Based on Threat and

$522 \quad$ Phylogeny. PLOS ONE 2:e296 
523 Isbell F et al. (2015) Biodiversity increases the resistance of ecosystem productivity to

$524 \quad$ climate extremes. Nature 526:574-577

525 Jansen PA et al. (2014) Negative density dependence of seed dispersal and seedling

526 recruitment in a Neotropical palm. Ecology Letters 17:1111-1120

527 Janzen DH (1986) The Future of Tropical Ecology. Annual Review of Ecology and Systematics

$528 \quad 17: 305-324$

529 Kang P et al. (2018) Linking ecosystem services and ecosystem health to ecological risk

530 assessment: A case study of the Beijing-Tianjin-Hebei urban agglomeration. Science

531 of The Total Environment 636:1442-1454

532 Keck F, Kahlert M (2019) Community phylogenetic structure reveals the imprint of dispersal-

533 related dynamics and environmental filtering by nutrient availability in freshwater

534 diatoms. Scientific Reports 9:1-8

535 Keddy PA (1992) Assembly and response rules: two goals for predictive community ecology.

$536 \quad$ Journal of Vegetation Science 3:157-164

537 Kendal D et al. (2018) A global comparison of the climatic niches of urban and native tree

538 populations. Global Ecology and Biogeography 27:629-637

539 Kraft NJB et al. (2015) Community assembly, coexistence and the environmental filtering

$540 \quad$ metaphor. Functional Ecology 29:592-599

541 Lambertz M, Dergam JA (2015) Mining disaster: Huge species impact. Nature 528:39-39 
542 Lebrija-Trejos E et al. (2010) Functional traits and environmental filtering drive community

$543 \quad$ assembly in a species-rich tropical system. Ecology 91:386-398

544 Leibold MA, Economo EP, Peres-Neto P (2010) Metacommunity phylogenetics: separating

545 the roles of environmental filters and historical biogeography. Ecology Letters

$546 \quad 13: 1290-1299$

547 Li L et al. (2018) Planting accelerates restoration of tropical forest but assembly mechanisms

548 appear insensitive to initial composition. Journal of Applied Ecology 55:986-996

549 Lopes W de P et al. (2002) Estrutura fitossocióloga de um trecho de vegetação arbórea no

550 Parque Estadual do Rio Doce - Minas Gerais, Brasil. Acta Botanica Brasilica 16:443-

$551 \quad 456$

552 Losos JB (2008) Phylogenetic niche conservatism, phylogenetic signal and the relationship

553 between phylogenetic relatedness and ecological similarity among species. Ecology

$554 \quad$ Letters 11:995-1003

555 Marangon LC et al. (2013) Relação entre vegetação e pedoformas na Mata do Paraiso,

556 Município de Viçosa, Minas Gerais. Revista Árvore 37:441-450

557 Matos FAR et al. (2020) Secondary forest fragments offer important carbon and biodiversity

558 cobenefits. Global Change Biology 26:509-522

559 Meira RMSA et al. (2016) Brazil's mining code under attack: giant mining companies impose

560 unprecedented risk to biodiversity. Biodiversity and Conservation 25:407-409

561 Meira-Neto JAA et al. (2018) Shading, nitrogen and soil texture rule a sandy savanna: Does

562 facilitation rule its patchy physiognomy as well? Flora 239:45-51 
563 Meira-Neto JAA, Neri AV (2017) Appealing the death sentences of the Doce, São Francisco

564 and Amazonas rivers: stopping the Mining Lobby and creating ecosystem services

565 reserves. Perspectives in Ecology and Conservation 15:199-201

566 Miazaki AS, Gastauer M, Meira-Neto JAA (2015) Environmental severity promotes

567 phylogenetic clustering in campo rupestre vegetation. Acta Botanica Brasilica

$568 \quad 29: 561-566$

569 Morales-Barbero J, Vega-Álvarez J (2019) Input matters matter: Bioclimatic consistency to

570 map more reliable species distribution models. Methods in Ecology and Evolution

$571 \quad 10: 212-224$

572 Mori AS (2016) Resilience in the Studies of Biodiversity-Ecosystem Functioning. Trends in

$573 \quad$ Ecology \& Evolution 31:87-89

574 Nazareno AG, Vitule JRS (2016) Pollution: Too many mining disasters in Brazil. Nature

$575 \quad 531: 580-580$

576 Neves DM et al. (2020) Evolutionary diversity in tropical tree communities peaks at

577 intermediate precipitation. Scientific Reports 10:1-7

578 Niño M et al. (2014) Long-term changes in above ground biomass after disturbance in a

579 neotropical dry forest, Hellshire Hills, Jamaica. Plant Ecology 215:1081-1097

580 Nunes S et al. (2019) Uncertainties in assessing the extent and legal compliance status of 581 riparian forests in the eastern Brazilian Amazon. Land Use Policy 82:37-47

582 Nunes W a. GA et al. (2000) Caracterização micropedológica de alguns solos da Zona da

583 Mata Mineira. Revista Brasileira de Ciência do Solo 24:103-115 
584 Oliveira AA de et al. (2014) Habitat specialization and phylogenetic structure of tree species

585 in a coastal Brazilian white-sand forest. Journal of Plant Ecology rtt073

586 Oliveira-Filho A (2014) NeoTropTree, Flora arbórea da Região Neotropical: Um banco de

587 dados envolvendo biogeografia, diversidade e conservação.

588 Oliveira-Filho AT, Fontes MAL (2000) Patterns of Floristic Differentiation among Atlantic

589 Forests in Southeastern Brazil and the Influence of Climate. BIOTROPICA 32:793-810

590 Oliveira-Junior ND et al. (2020) Identifying priority connectivity in a tropical forest hotspot

$591 \quad$ severely affected by land use changes. bioRxiv 2020.03.13.991372

592 Oliver TH et al. (2015) Biodiversity and Resilience of Ecosystem Functions. Trends in Ecology

$593 \quad$ \& Evolution 30:673-684

594 Paine CET et al. (2012) Phylogenetic density dependence and environmental filtering predict

595 seedling mortality in a tropical forest. Ecology Letters 15:34-41

596 Parmentier I et al. (2014) Prevalence of phylogenetic clustering at multiple scales in an

597 African rain forest tree community. Journal of Ecology 102:1008-1016

598 Phillips SJ, Anderson RP, Schapire RE (2006) Maximum entropy modeling of species

599 geographic distributions. Ecological Modelling 190:231-259

600 Pillar VD et al. (2013) Functional redundancy and stability in plant communities. Journal of

$601 \quad$ Vegetation Science 24:963-974

602 Pires APF et al. (2017) Forest restoration can increase the Rio Doce watershed resilience.

$603 \quad$ Perspectives in Ecology and Conservation 15:187-193 
604 Pontara V, Bueno ML, Scremin-Dias E (2016) Flooding avoidance Triplaris gardneriana

605 Wedd. (Polygonaceae): growth and morpho-anatomical aspects. Acta Scientiarum.

$606 \quad$ Biological Sciences

607 Poorter L et al. (2016) Biomass resilience of Neotropical secondary forests. Nature 530:211-

$608 \quad 214$

609 Qian H (2018) Climatic correlates of phylogenetic relatedness of woody angiosperms in

610 forest communities along a tropical elevational gradient in South America. Journal of

$611 \quad$ Plant Ecology 11:394-400

612 Qian H, Hao Z, Zhang J (2014) Phylogenetic structure and phylogenetic diversity of

613 angiosperm assemblages in forests along an elevational gradient in Changbaishan,

$614 \quad$ China. Journal of Plant Ecology 7:154-165

615 Reich PB et al. (2012) Impacts of Biodiversity Loss Escalate Through Time as Redundancy

$616 \quad$ Fades. Science 336:589-592

617 Singer D et al. (2018) Environmental filtering and phylogenetic clustering correlate with the

618 distribution patterns of cryptic protist species. Ecology 99:904-914

619 Soil Department of Universidade Federal de Vicosa (2020) Soil Map of Minas Gerais State.

620 Souza PB de et al. (2012) Distribution of tree species in a geomorphological and pedological

621 gradient of submontane semidecidual seasonal forest in the vicinity of Rio Doce

622 state park, Minas Gerais. Revista Árvore 36:707-718

623 Souza PB de et al. (2013) Diversity and phytosociological structure of a topographic gradient

624 in Seasonal Semidecidual Forest of Mata Mumbaça, MG. CERNE 19:489-499 
625 Swenson NG (2014) Functional and phylogenetic ecology in R. Springer, New York

626 Swenson NG (2009) Phylogenetic Resolution and Quantifying the Phylogenetic Diversity and Dispersion of Communities. PLoS ONE 4

628 Symonds MRE, Moussalli A (2011) A brief guide to model selection, multimodel inference

629 and model averaging in behavioural ecology using Akaike's information criterion.

$630 \quad$ Behavioral Ecology and Sociobiology 65:13-21

631 Tabarelli M, Peres CA (2002) Abiotic and vertebrate seed dispersal in the Brazilian Atlantic

632 forest: implications for forest regeneration. Biological Conservation 106:165-176

633 Temperton VM et al. (2005) Assembly Rules and Restoration Ecology: Bridging the Gap

634 Between Theory and Practice. Restoration Ecology 13:580-581

635 The Angiosperm Phylogeny Group (2016) An update of the Angiosperm Phylogeny Group

636 classification for the orders and families of flowering plants: APG IV. Botanical

637 Journal of the Linnean Society 181:1-20

638 Tilman D (1988) Plant Strategies and the Dynamics and Structure of Plant Communities.

$639 \quad$ Princeton University Press

640 Tonkin JD et al. (2017) Seasonality and predictability shape temporal species diversity.

$641 \quad$ Ecology $98: 1201-1216$

642 United States Geological Survey (2019) USGS EROS Archive - Digital Elevation - Shuttle Radar

643 Topography Mission (SRTM) 1 Arc-Second Global.

644 Walter H (1986) Vegetação e zonas climáticas: tratado de ecologia global. EPU, São Paulo 
645 Walter H, Lieth H (1967) Klimadiagramamm-Weltatlos. Paul. Gustav Fischer, Jena

646 Webb CO (2000) Exploring the Phylogenetic Structure of Ecological Communities: An

647 Example for Rain Forest Trees. The American Naturalist 156:145-155

648 Webb CO et al. (2002) Phylogenies and Community Ecology. Annual Review of Ecology and

$649 \quad$ Systematics 33:475-505

650 Webb CO, Donoghue MJ (2005) Phylomatic: tree assembly for applied phylogenetics.

$651 \quad$ Molecular Ecology Notes 5:181-183

652 Weber LC et al. (2014) Patterns of rain forest plant endemism in subtropical Australia relate

653 to stable mesic refugia and species dispersal limitations. Journal of Biogeography

$654 \quad 41: 222-238$

655 Weiher E et al. (2011) Advances, challenges and a developing synthesis of ecological

656 community assembly theory. Philosophical Transactions of the Royal Society B:

$657 \quad$ Biological Sciences 366:2403-2413

658 Weiher E, Keddy PA (1995) Assembly Rules, Null Models, and Trait Dispersion: New

659 Questions from Old Patterns. Oikos 74:159-164

660 Wiens JJ et al. (2010) Niche conservatism as an emerging principle in ecology and

661 conservation biology. Ecology Letters 13:1310-1324

662 Wolff S et al. (2018) Meeting global land restoration and protection targets: What would the 663 world look like in 2050? Global Environmental Change 52:259-272 
bioRxiv preprint doi: https://doi.org/10.1101/2020.04.04.022400; this version posted April 5, 2020. The copyright holder for this preprint (which

was not certified by peer review) is the author/funder, who has granted bioRxiv a license to display the preprint in perpetuity. It is made available under aCC-BY-NC-ND 4.0 International license.

664 Wüest RO et al. (2015) Available Climate Regimes Drive Niche Diversification during Range

665 Expansion. The American Naturalist 185:640-652

666 Zhao H et al. (2013) Spatial correlations between urbanization and river water pollution in

667 the heavily polluted area of Taihu Lake Basin, China. Journal of Geographical

$668 \quad$ Sciences 23:735-752

669 (2020) speciesLink Network - Herbário Virtual da Flora e dos Fungos.

670

671 
672

Table 1 - Phylogenetic signal of dispersal types as DispersalNRI (MPD), and DispersalNTI (MNTD) for anemochory, autochory, and zoochory. Dispersal types: AN - anemochory, AU - autochory, and ZO - zoochory. Calculated by Phylocom with randomization method 2, by mean of 999 runs. Ntaxa, number of species; MPD, mean phylogenetic distance calculated for species by actual data; MPD.rnd, mean phylogenetic distance calculated by randomization; NRI, Net Relatedness Index; MPD.rank.Low, how many times the MPD was lower than MPD.rnd; MPD. rank.Hi, how many times the MPD was higher than MPD.rnd; MNTD, mean nearest taxon distance calculated for species by actual data; MNTD.rnd, mean nearest taxon distance calculated by randomization; NTI, Nearest Taxon Index; MNTD.rank.Low, how many times the MNTD was lower than MNTD.rnd; MNTD.rank.Hi, how many times the MNTD was higher than MNTD.rnd; runs, number of randomizations. ${ }^{*} p<0.05, * * p<0.01, * * * p<0.001$.

\begin{tabular}{lclcccccc}
\hline Type & ntaxa & MPD & MPD.rnd & MPD.sd & NRI & MPD.rankLow & MPD.rankHi & runs \\
\hline AN & 330 & 209.0239 & 220.9857 & 1.4227 & $8.4076^{* * *}$ & 999 & 0 & 999 \\
AU & 161 & 191.2269 & 221.1116 & 2.0766 & $14.3909^{* * *}$ & 999 & 0 & 999 \\
ZO & 1432 & 221.3495 & 221.1048 & 0.3678 & -0.6653 & 247 & 752 & 999 \\
\hline Type & ntaxa & MNTD & MNTD.rnd & MNTD.sd & NTI & MNTD.rankLo & MNTD.rankHi & runs \\
\hline AN & 330 & 56.0852 & 61.3007 & 1.8922 & $2.7563^{* *}$ & 996 & 3 & 999 \\
AU & 161 & 67.5397 & 71.9932 & 3.4141 & 1.3044 & 899 & 100 & 999 \\
ZO & 1432 & 44.6573 & 48.8249 & 0.3891 & $10.71^{* * *}$ & 999 & 0 & 999 \\
\hline
\end{tabular}
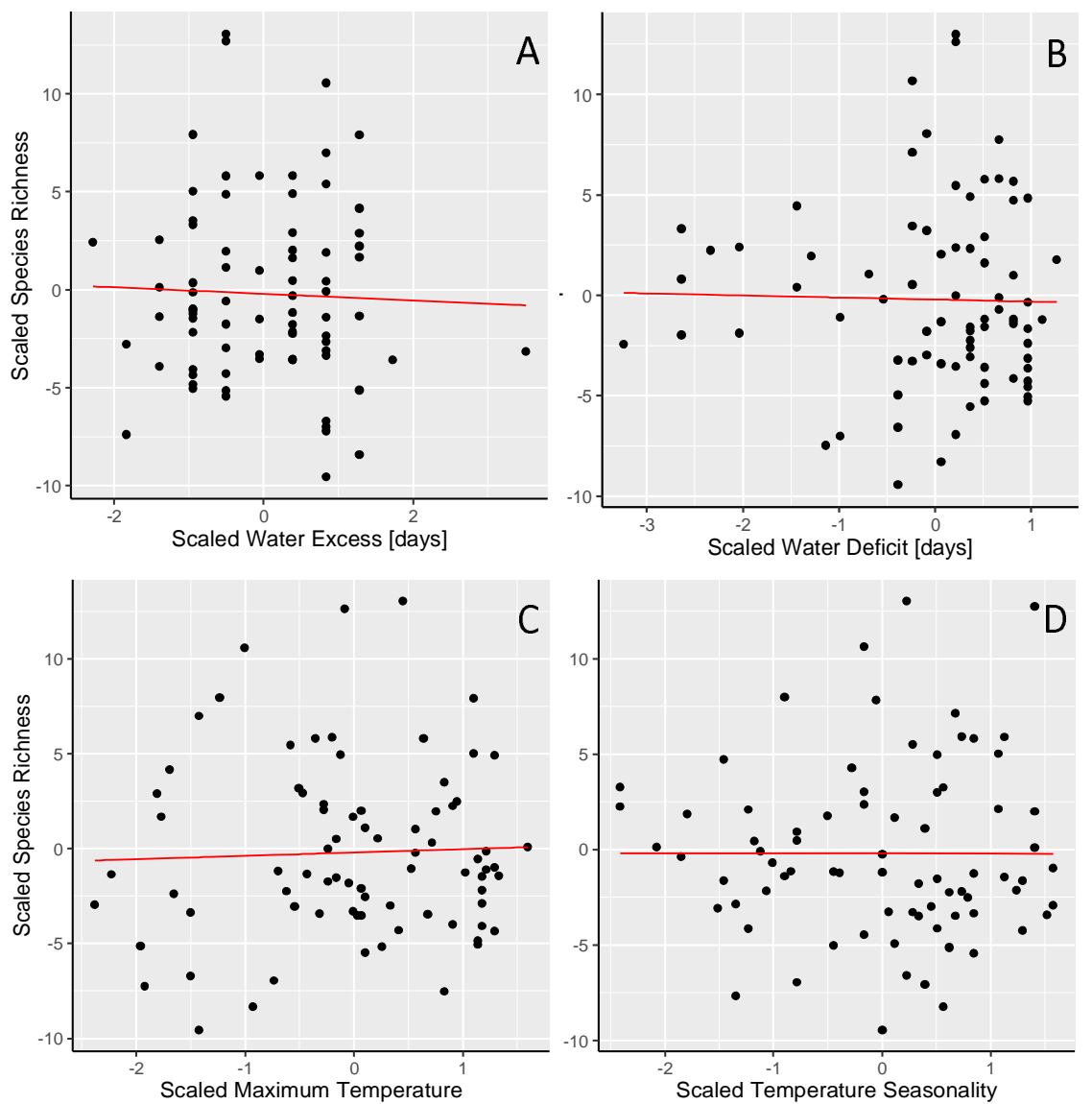

Figure 1 - The explanatory A- water excess duration (Water excess [days]), B- water deficit duration (Water deficit [days]), C- maximum temperature of the warmest month (Maximum temperature) and D- temperature seasonality and the response variable species richness of the global GLM model for fragments of the Rio Doce Basin, Brazil. Water excess duration (estimate $=-0.108760, P=4.82 \mathrm{e}-15$ ), water deficit duration (estimate = $0.108465, \mathrm{P}<2 \mathrm{e}-16$ ), maximum temperature of the warmest month (estimate $=0.073362, \mathrm{P}=4.47 \mathrm{e}-06$ ), temperature seasonality (estimate $=0.065411, \mathrm{P}=1.45 \mathrm{e}-13$ ). 

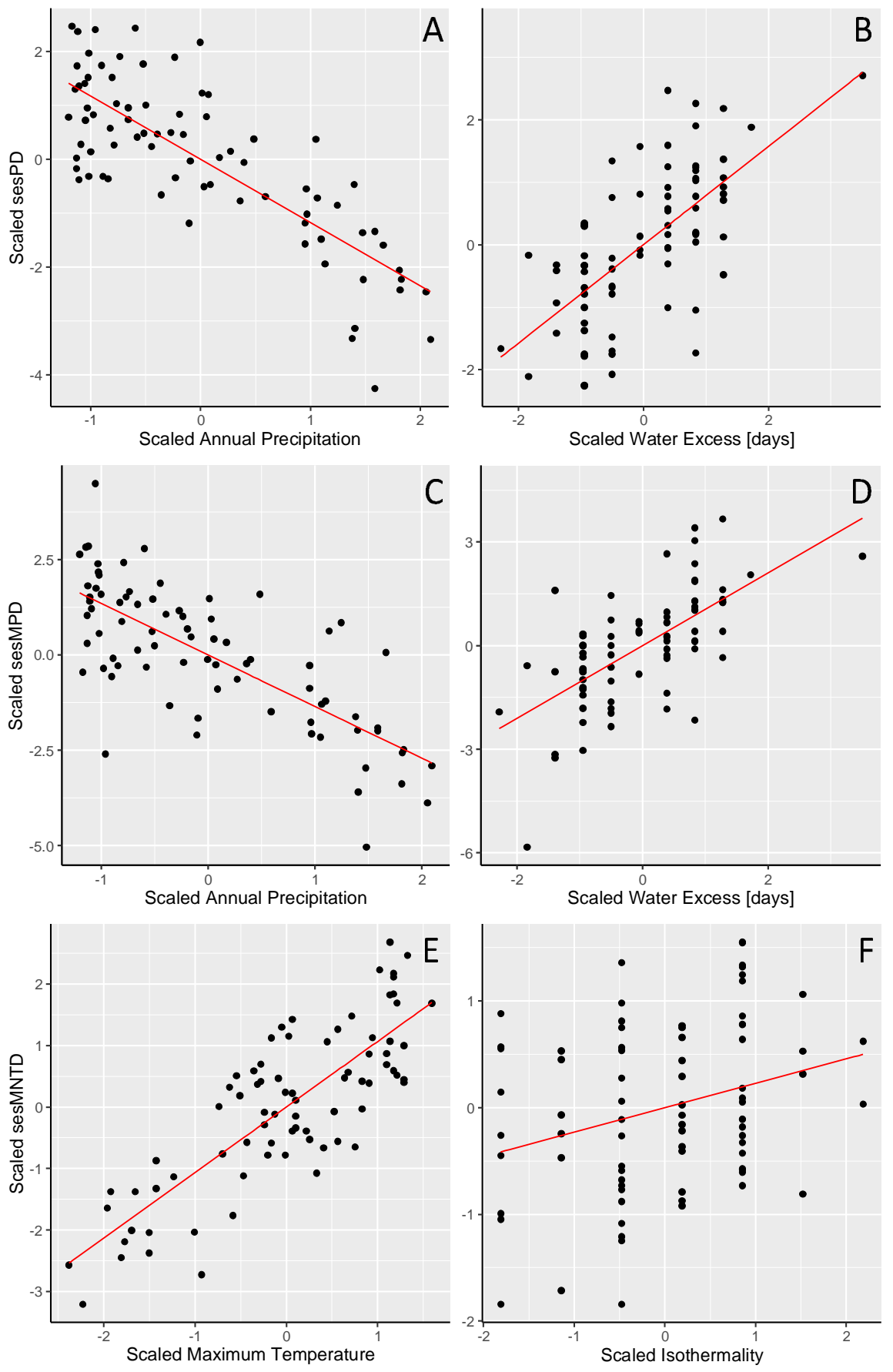

Figure 2 - A, and B - The explanatory variables mean annual precipitation (Annual precipitation) and water excess duration (Water excess [days]), and the response variable standard size effect of phylogenetic diversity (sesPD) of the global GLM model for fragments of the Rio Doce Basin, Brazil. Annual precipitation (estimate = $1.173858, \mathrm{P}=0.003$ ); Water excess (estimate $=0.786778, \mathrm{P}=0.00332$ ). $\mathrm{C}$, and $\mathrm{D}$ - The explanatory variables mean annual precipitation (Annual precipitation) and minimum temperature of the coldest month (Minimum Temperature) and the response variable standard size effect of mean phylogenetic distance (sesMPD) of the global GLM model for fragments of the Rio Doce Basin, Brazil. Annual precipitation (estimate $=-1.353912$, $\mathrm{P}=0.00357$ ); Water excess (estimate $=1.052365, \mathrm{P}=0.00368$ ). $\mathrm{E}$, and $\mathrm{F}$ - The explanatory variables maximum temperature of the warmth month, and the isothermality, the response variable of sesMNTD of the global 

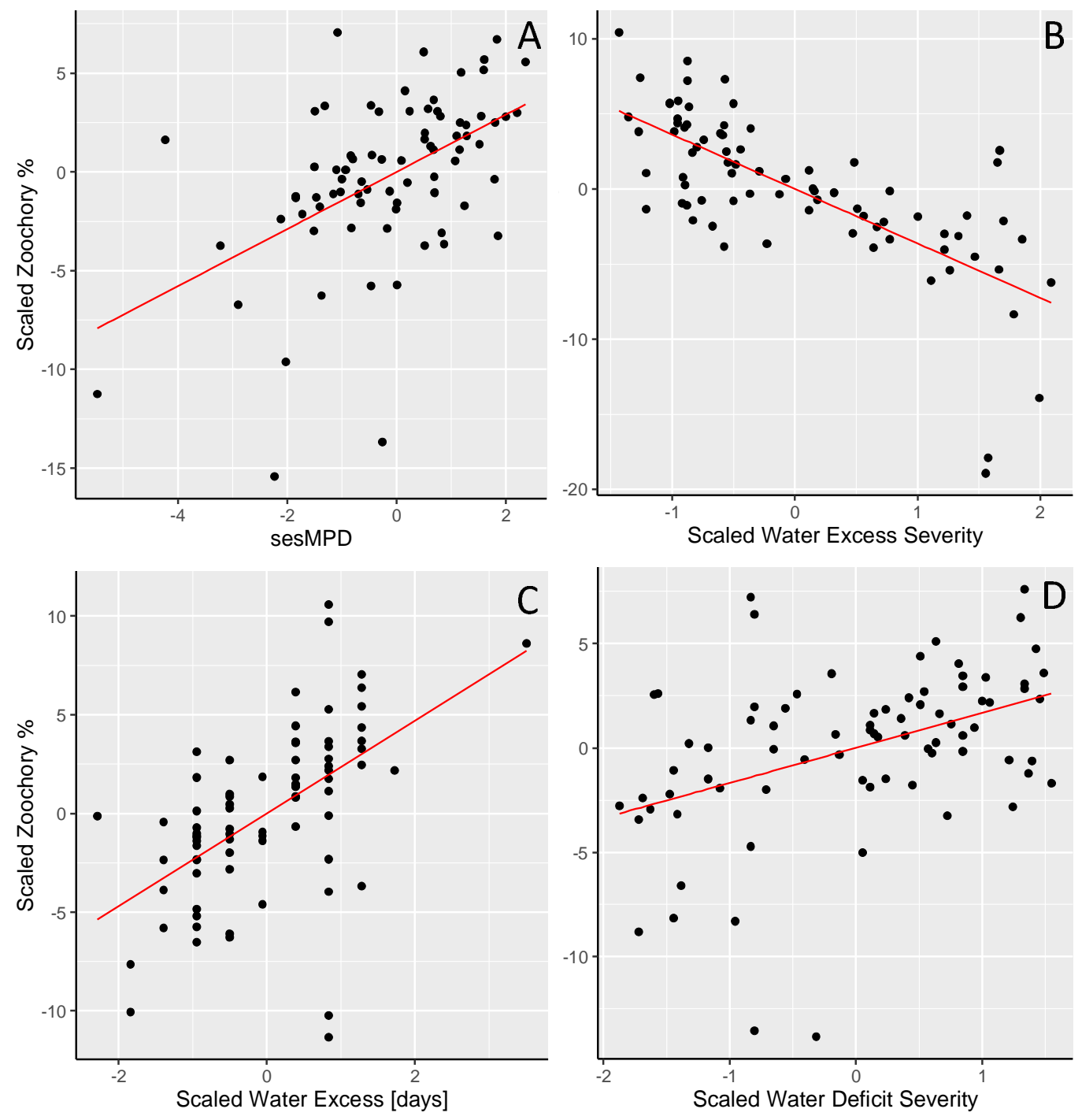

Figure 3 - The explanatory variables standard size effect of A- mean phylogenetic distance (sesMPD), B- water excess severity, C- water excess duration (Water excess [days]), D- water deficit severity, and the response variable percentage of species with zoochory (Zoochory \%) of the global GLM model for fragments of the Rio Doce Basin, Brazil. SesMPD (estimate $=1.4483, \mathrm{P}=1.56 \mathrm{e}-05$ ), water excess severity (estimate $=-3.6250, \mathrm{P}=$ 1.84e-05), water excess duration (estimate $=2.3493, P=0.0144$ ), water deficit severity (estimate $=1.6785$, $\mathrm{P}=0.01964)$. 

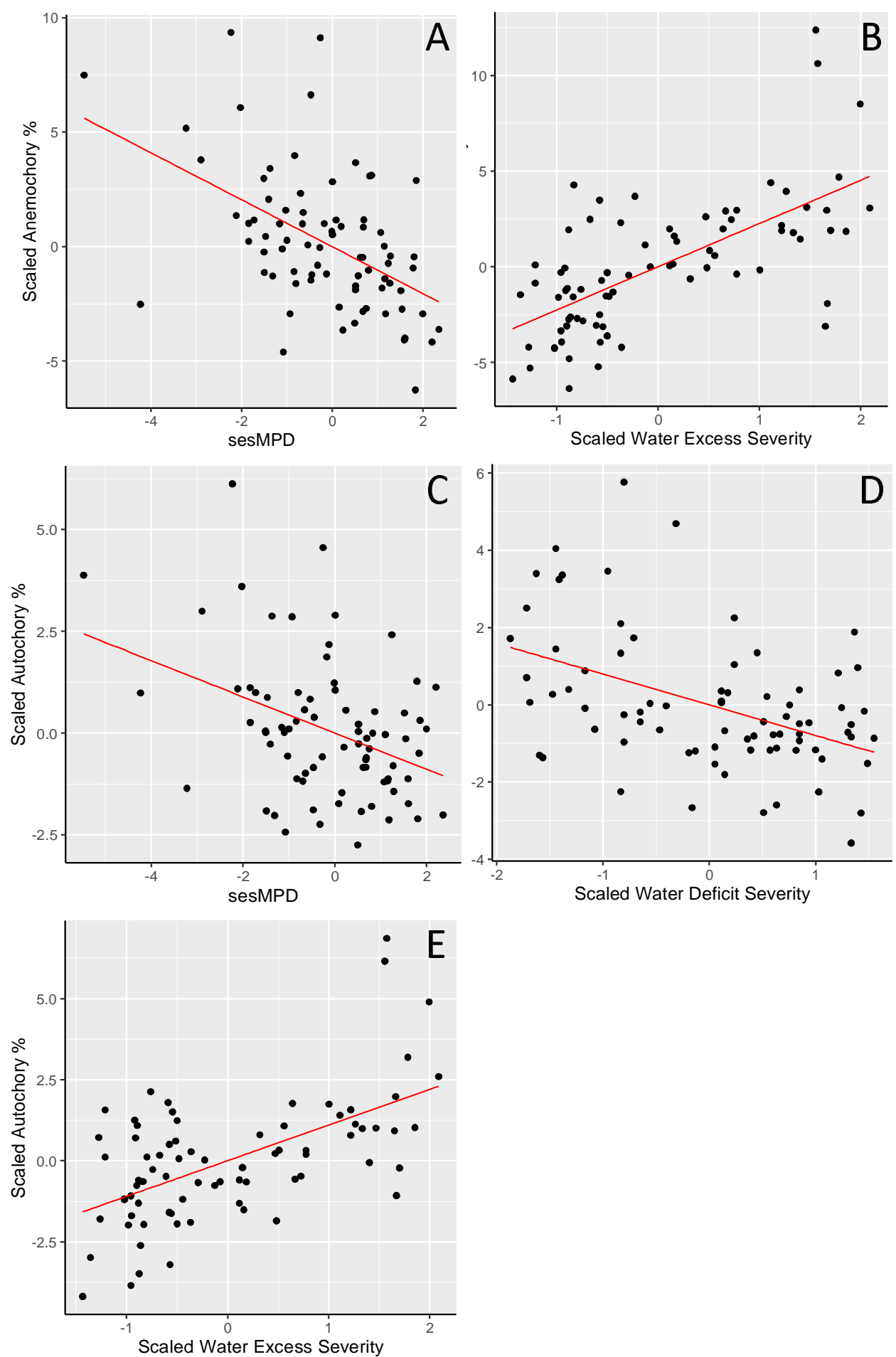

Figure 4 - A, and B- The explanatory variables standard size effect of mean phylogenetic distance (sesMPD),

water excess severity and the response variable percentage of species with anemochory (Anemochory \%) of the global GLM model for fragments of the Rio Doce Basin, Brazil. SesMPD (estimate $=-1.02441, P=4.82 e-05$ ), water excess severity (estimate $=2.26164, \mathrm{P}=0.00181$ ). $\mathrm{C}, \mathrm{D}$, and $\mathrm{E}$ - The explanatory variables standard size effect of mean phylogenetic distance (sesMPD), water deficit severity, and water excess severity, and the response variable percentage of species with autochory (Autochory \%) of the global GLM model for fragments of the Rio Doce Basin, Brazil. SesMPD (estimate $=-0.4452, P=0.00186$ ), water deficit severity (estimate $=-$ $0.7936, \mathrm{P}=0.00935$ ), water excess severity (estimates $=1.1008, \mathrm{P}=0.00188$ ). 